PAPER

\title{
Early circulating levels of endothelial cell activation markers in aneurysmal subarachnoid haemorrhage: associations with cerebral ischaemic events and outcome
}

\author{
C J M Frijns, R Fijnheer, A Algra, J A van Mourik, J van Gïn, G J E Rinkel
}

J Neurol Neurosurg Psychiatry 2006;77:77-83. doi: 10.1136/jnnp.2005.064956

See end of article for authors' affiliations

.....................

Correspondence to: Dr C J M Frijns, Department of Neurology, C03.228, University Medical Centre, PO Box 85500, 3508 GA Utrecht, Netherlands; c.j.m.frijns@ neuro.azu.nl

Received 11 February 2005 In revised form 5 July 2005 Accepted 6 July 2005

\begin{abstract}
Objective: To investigate the relation of endothelial cell activation with delayed cerebral ischaemia (DCI) and outcome after subarachnoid haemorrhage (SAH).

Methods: Concentrations of soluble (s) intercellular adhesion molecule-1, sE-selectin, sP-selectin, ED1fibronectin, von Willebrand Factor (vWf), and vWf propeptide were measured within three days of SAH onset. The associations with poor outcome were investigated at three months in 106 patients. In 90 patients in whom the occurrence of cerebral ischaemia could be dated accurately, two analyses were undertaken: one for all ischaemic events $(n=32)$, including those related to treatment, and another for spontaneous DCl $(n=11)$. Concentrations of markers were dichotomised at their medians. The associations of endothelial cell activation markers with outcome were expressed as odds ratios (OR) from logistic regression and those with ischaemic events as hazard ratios (HR) derived from Cox regression.

Results: Early vWf concentrations were associated with poor outcome (crude OR=4.6 $195 \% \mathrm{Cl}, 2.0$ to 10.9; adjusted $O R=3.3$ (1.1 to 9.8). Early levels of $\mathrm{vWf}$ were also positively related to occurrence of all ischaemic events (crude $H R=2.3$ (1.1 to 4.9); adjusted $H R=1.8$ (0.8 to 3.9) and with occurrence of spontaneous DCl (crude HR=3.5 (0.9 to 13.1); adjusted HR=2.2 (0.5 to 9.8). None of the other markers showed any associations.

Conclusions: Concentrations of sICAM-1, sP-selectin, sE-selectin, and EDI-fibronectin do not predict the occurrence of $\mathrm{DCl}$ or outcome. The positive associations of raised early vWf concentrations with ischaemic events and poor outcome after SAH may reflect a predisposition to further ischaemic injury through formation of microthrombi in the cerebral circulation.
\end{abstract}

$\mathrm{P}$ atients who survive the initial hours after onset of subarachnoid haemorrhage (SAH) are prone to several major complications. In a large proportion of patients delayed cerebral ischaemia (DCI) develops, often with devastating consequences. ${ }^{1}$ This complication is partially related to arterial narrowing, but its pathogenesis is incompletely understood. Local inflammatory changes may play a role, in large vessels as well as in the microcirculation. ${ }^{2}$ Recently, the involvement of endothelial cell activation and inflammatory adhesion molecules in both experimental and human SAH has been emphasised in several reports. ${ }^{3-9}$

Our aim in the present study was to assess the relation between concentrations of circulating markers of endothelial cell activation early after the onset of SAH, and the occurrence of delayed cerebral ischaemia and poor outcome after SAH. In the cerebral (micro-)circulation, increased expression of inflammatory adhesion molecules (intercellular adhesion molecule-1 (ICAM-1), P-selectin, and E-selectin) can lead to adhesion of inflammatory cells, thus promoting local inflammation, vessel wall changes, thrombosis, and plugging of small vessels with leucocytes. In this way, inflammatory adhesion molecules could play a pathogenic role in the development of delayed cerebral ischaemia and therefore be a target for future therapeutic strategies, for example with monoclonal antibodies. ${ }^{10}{ }^{11}$

We included measurements of cellular EDl-fibronectin, von Willebrand factor (vWf), and vWf propeptide as additional markers of endothelial cell activation. Under normal circumstances, endothelial cells do not express the extra type III domain (EDl, or EDA/EDIII), but in pathological conditions of the vessel wall-for example induced by hypertension-the EDl domain is inserted into fibronectin by alternative splicing. ${ }^{12-14}$ Von Willebrand factor is a large adhesive glycoprotein that serves as a marker of both acute and chronic endothelial cell activation. The vWf propeptide is linked to vWf. Upon activation of endothelial cells, both are released in equimolar amounts. The plasma half life of the propeptide is shorter than the half life of vWf. Thus a high concentration of vWf propeptide suggests acute rather than chronic endothelial cell activation. ${ }^{15}$

\section{METHODS \\ Patients}

Blood was sampled in 128 consecutive patients admitted to the University Medical Centre Utrecht with a clinical diagnosis of SAH and computed tomography (CT) showing subarachnoid blood (fig 1). Patients were not eligible if they were admitted more than 72 hours after onset, if death appeared imminent on admission, or if we could not obtain informed consent. We subsequently excluded patients with a perimesencephalic haemorrhage $(n=10)$ or with SAH from other non-aneurysmal causes $(n=3)$, patients in whom the presence of an aneurysm could not be demonstrated $(n=8)$, and one patient because of insufficient blood sampling. In the remaining 106 patients the diagnosis of aneurysmal SAH was based on a typical medical history, CT confirming the presence of subarachnoid haemorrhage with an aneurysmal pattern, and CT angiography or intra-arterial angiography showing the presence of an aneurysm.

Abbreviations: $\mathrm{DCl}$, delayed cerebral ischaemia; GCS, Glasgow coma scale; mRs, modified Rankin scale; $\mathrm{SAH}$, subarachnoid haemorrhage; vWf, von Willebrand factor 
Informed consent was obtained from all patients or their representatives. The study was approved by the institutional review board.

Patients were admitted to a medium care or intensive care unit depending on their clinical condition. They were under continuous observation, with monitoring of ECG, pulse rate, blood pressure, and temperature, and frequent assessment of the Glasgow coma scale (GCS), fluid balance, and laboratory data. Medical treatment consisted of oral administration of nimodipine and intravenous administration of fluid aimed at maintenance of a neutral fluid balance.

\section{Data collection}

We collected all clinical, laboratory, and radiological data from the medical records and the hospital registry system. For each patient an anonymised medical history was produced which included a description of the radiological data. Diminished or absent cerebral blood flow during and after the rupture of an aneurysm may lead to acute cerebral ischaemia. Acute cerebral ischaemia was defined as the occurrence of focal signs or loss of consciousness, including epileptic seizures, at the time of aneurysmal rupture that could not be explained by acute hydrocephalus, intraparenchymous haemorrhage, or haemodynamic or respiratory disturbances. The clinical condition at admission was classified according to the World Federation of
Neurosurgical Societies (WFNS) scale. ${ }^{16}$ Hypertension, diabetes, immunological disorders, hypercholesterolaemia, infectious disease, or cancer were recorded as relevant comorbidity because they are associated with an increase in circulating endothelial cell activation markers. The amount of blood on the initial CT was assessed using the Hijdra score. ${ }^{17}$

\section{Blood sampling and laboratory investigations}

Blood was collected within 72 hours of onset of the haemorrhage with an evacuated tube system into $3.1 \%$ citrate $(1: 10)$ and was immediately centrifuged at $2000 \times g$ for 15 minutes at $4^{\circ} \mathrm{C}$. The supernatant was removed and centrifuged a second time. Plasma samples were stored at $-70^{\circ} \mathrm{C}$. We assessed soluble (s)ICAM-1, sP-selectin, and sEselectin with commercially available enzyme linked immunosorbent assays (ELISA) (Kordia, Leiden, Netherlands). vWf propeptide and vWf were measured at the Department of Blood Coagulation, Sanquin, Amsterdam, Netherlands, as described previously. ${ }^{15}$ We measured circulating cellular ED1fibronectin with an ELISA developed at the University Medical Centre Utrecht, in which the primary antibody was IgM monoclonal antibody (mAb) 3E2 (Sigma, St Louis, Missouri, USA) against EDl-fibronectin, and ligand capture was detected with peroxidase conjugated rabbit anti-human fibronectin (Dako, Glostrup, Denmark). ${ }^{13} 18$ The concentrations of each marker were dichotomised at the median value,

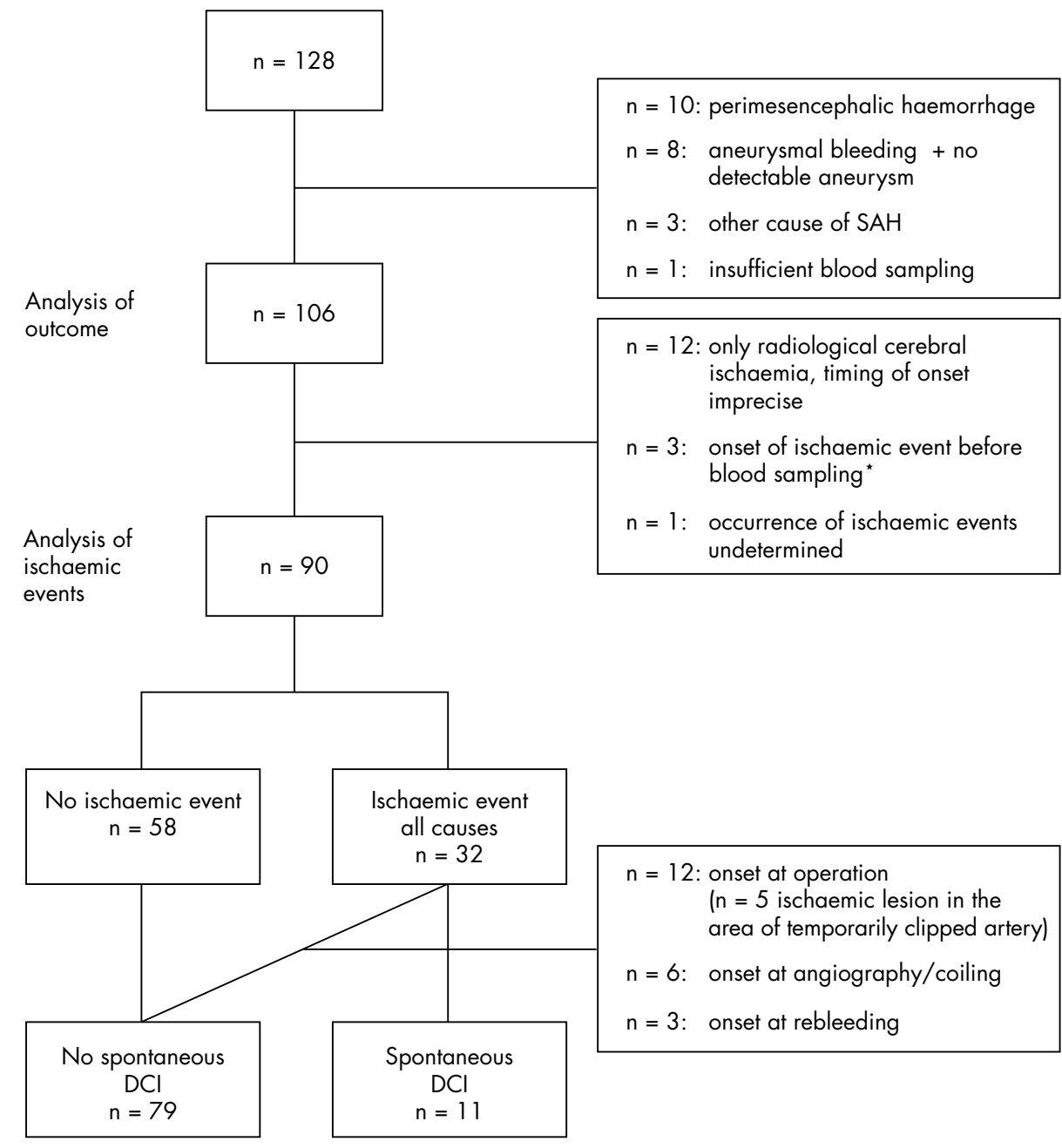

*In one patient ischaemic event at operation, in one at rebleeding and in one spontaneous $\mathrm{DCl}$.

Figure 1 Flow chart of selection of subgroups and reasons for exclusion. DCl, delayed cerebral ischaemia. 
because there are no clinically established cut off values to distinguish normal from abnormal for most of these markers. Dichotomisation at the median also offers an optimal distribution for statistical analysis.

\section{Assessment and analysis of outcome}

Outcome at three months after onset of SAH was determined using the modified Rankin scale (mRs) score ${ }^{19}$ by means of a telephone interview with the patients or their relatives between 12 and 14 weeks after onset. As we did in previous studies from our research group, we predefined outcome according to the ability to live at home or not as good (mRs 0-3) or poor (mRs 4-5 and death). We calculated odds ratios $(\mathrm{OR})$ to determine the relation between circulating markers of endothelial cell activation and poor outcome with logistic regression analysis (SPSS 9.0 statistical package). The influence of confounding variables on the concentrations of the different markers was calculated in a bivariate logistic regression analysis with adjustment for age, sex, WFNS at admission (score 1-5), loss of consciousness at time of aneurysm rupture (GCS <14, present or absent), loss of consciousness at the time of aneurysm rupture (none, any, or lasting more than one hour), signs of acute ischaemia at the time of aneurysm rupture (present or absent), amount of intracisternal blood (score 0-30), ${ }^{17}$ amount of intraventricular blood (score 0-10), ${ }^{17}$ delay of blood sampling after onset of SAH (days), presence of relevant comorbidity (present or absent), and use of statins (present or absent). From the results of the bivariate analyses we selected the variables that

\begin{tabular}{|c|c|}
\hline Female sex & $72(68 \%)$ \\
\hline Age (years) & $54(21$ to 79$)$ \\
\hline Hypertension & $32(30 \%)$ \\
\hline Diabetes mellitus & $2(2 \%)$ \\
\hline Hypercholesterolaemia & $11(10 \%)$ \\
\hline Use of statins & $10(9 \%)$ \\
\hline Day of admission & $0(0-2)$ \\
\hline \multicolumn{2}{|l|}{ WFNS at admission: } \\
\hline I & $45(43 \%)$ \\
\hline ॥ & $31(29 \%)$ \\
\hline III & $5(5 \%)$ \\
\hline IV & $18(17 \%)$ \\
\hline $\mathrm{V}$ & $7(7 \%)$ \\
\hline Acute ischaemia & $47(44 \%)$ \\
\hline Amount of cisternal blood (ml) & $22(0$ to 29$)$ \\
\hline Amount of intraventricular blood (ml) & $2(1$ to 11$)$ \\
\hline Rebleeding & $14(13 \%)$ \\
\hline \multicolumn{2}{|l|}{ Treatment of aneurysm: } \\
\hline operative clipping & $78(74 \%)$ \\
\hline coiling & $13(12 \%)$ \\
\hline none & $15(14 \%)$ \\
\hline \multicolumn{2}{|l|}{ Timing of treatment: } \\
\hline $\begin{array}{l}\text { day of operation } \\
\text { day of coiling }\end{array}$ & $\begin{array}{l}3.5(0 \text { to } 65) \\
3(2 \text { to } 17)\end{array}$ \\
\hline \multicolumn{2}{|l|}{ Ischaemic events* } \\
\hline none & $58(55 \%)$ \\
\hline radiologically only & $12(11 \%)$ \\
\hline clinically only & $4(4 \%)$ \\
\hline both & $31(29 \%)$ \\
\hline undetermined & $1(1 \%)$ \\
\hline \multicolumn{2}{|l|}{ Onset of symptomatic ischaemic events } \\
\hline at operation & $13(37 \%)$ \\
\hline at coiling/angiography & $6(17 \%)$ \\
\hline at rebleeding & $4(11 \%)$ \\
\hline spontaneously & $12(34 \%)$ \\
\hline Outcome at three months & \\
\hline good (mRs 0-3) & $66(62 \%)$ \\
\hline poor (mRs 4-5) & $18(17 \%)$ \\
\hline dead & $22(21 \%)$ \\
\hline \multicolumn{2}{|c|}{$\begin{array}{l}\text { Data are } \mathrm{n}(\%) \text { or median (range). } \\
\text { *All causes, including operation or procedure related. } \\
\text { mRs, modified Rankin scale; WFNS, World Federation of } \\
\text { Neurosurgical Societies scale. }\end{array}$} \\
\hline
\end{tabular}

changed the crude OR of each marker by more than $5 \%$ for use in the multivariate analysis. Although we consider rebleeding as an important determinant of outcome, we did not include rebleeding in the multivariate analysis as its occurrence is unknown at the time of admission. Crude and multivariate adjusted OR are presented with their respective 95\% confidence intervals (CI).

\section{Assessment of ischaemic events}

Ischaemic events were subdivided as follows: clinical episode of cerebral ischaemia with compatible new ischaemic lesions on CT; clinical episode of cerebral ischaemia without compatible ischaemic abnormalities on CT or magnetic resonance imaging (MRI) and no explanation for the clinical manifestations other than ischaemia; radiological cerebral ischaemia consisting of new and persisting ischaemic lesions on repeat CT or MRI without corresponding clinical changes.

In order not to overlook any episodes of cerebral ischaemia, clinical ischaemic events were defined as a deterioration in the level of consciousness consisting of a decrease in the GCS of 1 point or more, or the appearance of focal signs, which lasted for at least one hour and could not be explained by recurrent bleeding, hydrocephalus, or metabolic disturbances. Other causes were excluded by CT of the brain and laboratory tests as soon as the deterioration was observed. We did not routinely undertake angiography or transcranial Doppler investigations to show vasospasm. All initial and follow up CTs were reviewed by the principal investigator (CJMF). Ischaemic lesions were defined as new hypodense lesions that were not visible on the initial CT and persisted on follow up CT or MRI.

The occurrence of ischaemic events was independently assessed by two experienced neurologists, one of whom based the assessment on the anonymised history. In cases of conflicting opinions, a consensus meeting led to agreement in all instances. In case of doubt with respect to ischaemic lesions on CT or MRI, these were reviewed retrospectively by the second observer (GJER). At the time of clinical and radiological assessment neither observer was aware of the concentrations of the endothelial cell activation markers.

\section{Analysis of cerebral ischaemic events}

Sixteen patients were excluded from this analysis (fig 1 ). In 12 patients with only radiological ischaemia it was impossible to determine accurately whether or not new ischaemic lesions had developed during the acute phase after aneurysm rupture, at the time of operation or endovascular treatment of the aneurysm, or spontaneously. Three other patients were excluded because of onset of the ischaemic event before blood could be sampled. In two of these patients the ischaemic event was related to early rebleeding or clipping of the aneurysm. In one patient occurrence of an ischaemic event could not be assessed because of prolonged sedation on the intensive care unit for severe haemodynamic and respiratory problems that precluded clinical assessment and cerebral CT.

We calculated hazard ratios (HR) with the Cox proportional hazard regression model (SPSS 9.0 statistical package) to assess the relation between concentrations of circulating markers of endothelial cell activation and the risk of cerebral ischaemic events. Patients were censored at time of first rebleeding, at death, at the first cerebral ischaemic event, or at the 21 st day after onset, whichever came first. Crude hazard ratios for occurrence of cerebral ischaemic events are presented with their 95\% confidence intervals. The relevant variables adjusted for in the multivariate regression analysis resulted from bivariate Cox regression analysis with the same 11 variables as for outcome. 
Table 2 Crude and multivariate adjusted odds ratios (OR) for poor outcome at three months (by modified Rankin scale) as predicted by dichotomised initial concentrations $(<$ or $\geqslant$ median) of endothelial cell activation markers $(n=106)$

\begin{tabular}{|c|c|c|c|c|}
\hline \multirow[b]{2}{*}{ Variable } & \multicolumn{2}{|c|}{ Crude OR } & \multicolumn{2}{|c|}{ Adjusted OR } \\
\hline & OR & $(95 \% \mathrm{Cl})$ & OR & (95\% CI) \\
\hline $\begin{array}{l}\text { vWf } \geqslant 94.5 \mathrm{nmol} / \mathrm{l} \\
\text { vWf propeptide } \geqslant 7.75 \mathrm{nmol} / \mathrm{l} \\
\text { EDl-fibronectin } \geqslant 2.25 \mu \mathrm{g} / \mathrm{l} \\
\mathrm{sICAM}-1 \geqslant 401 \mathrm{ng} / \mathrm{ml} \\
\mathrm{sP} \text {-selectin } \geqslant 92.5 \mathrm{ng} / \mathrm{ml} \\
\mathrm{sE} \text {-selectin } \geqslant 40.0 \mathrm{ng} / \mathrm{ml}\end{array}$ & $\begin{array}{l}4.6 \\
3.2 \\
2.3 \\
1.4 \\
1.6 \\
1.1\end{array}$ & $\begin{array}{l}(2.0 \text { to } 10.9) \\
(1.4 \text { to } 7.3) \\
(1.0 \text { to } 5.1) \\
(0.7 \text { to } 3.2) \\
(0.7 \text { to } 3.6) \\
(0.5 \text { to } 2.4)\end{array}$ & $\begin{array}{l}3.3 \\
2.1 \\
1.0 \\
1.2 \\
1.3 \\
1.0\end{array}$ & $\begin{array}{l}(1.1 \text { to } 9.8) \\
(0.8 \text { to } 5.6) \\
(0.9 \text { to } 1.2) \\
(0.5 \text { to } 3.0) \\
(0.5 \text { to } 3.3) \\
(0.4 \text { to } 2.7)\end{array}$ \\
\hline \multicolumn{5}{|c|}{$\begin{array}{l}\text { vWf adjusted for: age, WFNS, intracisternal amount of blood, intraventricular amount of blood, signs of acute } \\
\text { ischaemia, loss of consciousness at the time of aneurysm rupture, vWf propeptide adjusted for: age, WFNS, } \\
\text { intracisternal amount of blood, intraventricular amount of blood, loss of consciousness at the time of aneurysm } \\
\text { rupture. } \\
\text { EDI-fibronectin adjusted for: relevant comorbidity, age, sex, WFNS, amount of intracisternal blood, amount of } \\
\text { intraventricular blood, loss of consciousness at the time of aneurysm rupture. } \\
\text { sICAM-1 adjusted for: age, sex, signs of acute ischaemia, loss of consciousness at the time of aneurysm rupture. } \\
\text { sP-selectin adjusted for: age, WFNS, amount of intracisternal blood, amount of intraventricular blood, signs of } \\
\text { acute ischaemia, loss of consciousness at the time of aneurysm rupture. } \\
\text { sE-selectin adjusted for: age, amount of intracisternal blood, amount of intraventricular blood, signs of acute } \\
\text { ischaemia, loss of consciousness at the time of aneurysm rupture. } \\
\text { vWf, von Willebrand factor; WFNS, World Federation of Neurosurgical Societies scale. }\end{array}$} \\
\hline
\end{tabular}

We designed two analyses of associations between markers of endothelial cell activation and ischaemic events. For the first analysis all patients with ischaemic events were taken into account irrespective of the presumed cause. For example, patients with an ischaemic event that occurred within 24 hours of angiography, clipping, or coiling of the aneurysm were included in this analysis. For the second analysis, which
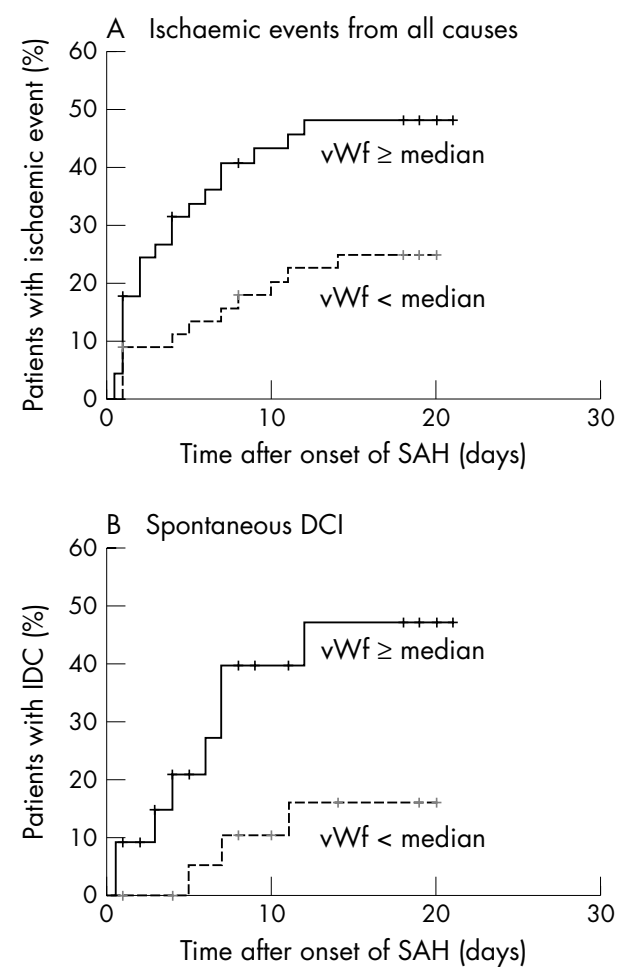

Figure 2 (A) Survival curve of the occurrence of cerebral ischaemic events from all causes in patients with early von Willebrand factor (vWf) concentrations below the median or $\geqslant$ the median value. (B) Survival curve of the occurrence of spontaneous delayed cerebral ischaemia in patients with early $\mathrm{vWf}$ concentrations below or $\geqslant$ the median value. DCI, delayed cerebral ischaemia; SAH, subarachnoid haemorrhage; vWf, von Willebrand factor. was intended to include only spontaneous DCI, we excluded ischaemic events that were diagnosed within two days after angiography, endovascular procedure, or operation of the aneurysm.

\section{RESULTS \\ Patients}

The clinical characteristics of the patients are presented in table 1. A decrease in the level of consciousness (GCS <14) from any cause at the time of aneurysm rupture was reported in 69 of the 106 patients (65\%). Twenty five patients (24\%) were in poor clinical condition on admission (WFNS IV-V). Relevant comorbidity was present in 45 patients (42\%). Ischaemic events occurred in 47 patients (44\%), including 12 with only radiological ischaemia and four with cerebral ischaemia after rebleeding. The median day of occurrence of ischaemic events was day 4. In all but two of the patients ischaemic events occurring before day 4 were related to rebleeding or to operation or coiling of the aneurysm. Clinical symptoms in the 35 patients with symptomatic cerebral ischaemia consisted of a decrease in the GCS score ranging from 2 to 8 (median 5.5) in 10 patients, both a decrease in the GCS score and hemiparesis in seven, paresis of one or two limbs without a decrease in consciousness in 14, isolated aphasia in one, and an isolated cognitive disorder in three.

\section{Endothelial cell activation markers and outcome}

Crude and adjusted odds ratio for poor outcome are presented in table 2 . In the univariate analysis, patients with vWf concentrations $\geqslant$ median had an increased risk of poor outcome $(\mathrm{OR}=4.6$ (95\% CI, 2.0 to 10.9)). This association remained statistically significant after multivariate adjustment $(\mathrm{OR}=3.3(1.1$ to 9.8$))$.

\section{Endothelial cell activation markers and cerebral ischaemic events}

The analysis of associations with ischaemic events was carried out in 90 patients, 32 of whom had experienced clinical episodes of DCI either spontaneously or related to treatment or rebleeding of the aneurysm (fig 1). In 11 cases ischaemic events met the criteria for spontaneous development. Crude and adjusted hazard ratios for the occurrence of ischaemic events from any cause and for the occurrence of spontaneous DCI are given in table 2. The analysis of 
Table 3 Crude and multivariate adjusted hazard ratios for ischaemic events as predicted by dichotomised concentrations $(<$ or $\geqslant$ median) of endothelial cell activation markers

\begin{tabular}{|c|c|c|c|c|c|c|c|c|}
\hline \multirow[b]{3}{*}{ Variable } & \multicolumn{4}{|c|}{ All ischaemic events } & \multicolumn{4}{|c|}{ Spontaneous DCI } \\
\hline & \multicolumn{2}{|c|}{ Crude HR } & \multicolumn{2}{|c|}{ Adjusted HR } & \multicolumn{2}{|c|}{ Crude HR } & \multicolumn{2}{|c|}{ Adjusted HR } \\
\hline & $\mathrm{HR}$ & $(95 \% \mathrm{Cl})$ & $\mathrm{HR}$ & $(95 \% \mathrm{Cl})$ & $\mathrm{HR}$ & $(95 \% \mathrm{Cl})$ & $\mathrm{HR}$ & $(95 \% \mathrm{Cl})$ \\
\hline $\begin{array}{l}\mathrm{vWf} \geqslant 93.0 \mathrm{nmol} / \mathrm{l} \\
\mathrm{vWf} \text { propeptide } \geqslant 7.70 \mathrm{nmol} / / \\
\text { ED - fibronectin } \geqslant 2.15 \mu \mathrm{g} / / \\
\text { s } C \text { CAM-1 } \geqslant 376.5 \mathrm{ng} / \mathrm{ml} \\
\mathrm{Sp} \text {-selectin } \geqslant 92.5 \mathrm{ng} / \mathrm{ml} \\
\text { sE-selectin } \geqslant 41.5 \mathrm{ng} / \mathrm{ml}\end{array}$ & $\begin{array}{l}2.3 \\
1.1 \\
1.2 \\
1.0 \\
1.5 \\
0.8\end{array}$ & $\begin{array}{l}(1.1 \text { to } 4.9) \\
(0.6 \text { to } 2.3) \\
(0.6 \text { to } 2.4) \\
(0.5 \text { to } 2.1) \\
(0.8 \text { to } 3.1) \\
(0.4 \text { to } 1.6)\end{array}$ & $\begin{array}{l}1.8 \\
0.8 \\
0.9 \\
0.9 \\
1.5 \\
0.7\end{array}$ & $\begin{array}{l}(0.8 \text { to } 3.9) \\
(0.4 \text { to } 1.7) \\
(0.4 \text { to } 2.0) \\
(0.5 \text { to } 1.9) \\
(0.6 \text { to } 3.3) \\
(0.3 \text { to } 1.6)\end{array}$ & $\begin{array}{l}3.5 \\
1.0 \\
1.8 \\
0.9 \\
1.3 \\
0.5\end{array}$ & $\begin{array}{l}(0.9 \text { to } 13.1) \\
(0.3 \text { to } 3.3) \\
(0.5 \text { to } 6.1) \\
(0.3 \text { to } 2.9) \\
(0.4 \text { to } 4.2) \\
(0.1 \text { to } 1.7)\end{array}$ & $\begin{array}{l}2.2 \\
0.7 \\
1.5 \\
1.3 \\
0.8 \\
0.5\end{array}$ & $\begin{array}{l}(0.5 \text { to } 9.8) \\
(0.2 \text { to } 2.7) \\
(0.4 \text { to } 5.4) \\
(0.4 \text { to } 5.0) \\
(0.2 \text { to } 3.1) \\
(0.2 \text { to } 1.8)\end{array}$ \\
\hline \multicolumn{9}{|c|}{$\begin{array}{l}\text { vWf: adjusted for amount of intracisternal blood, signs of acute ischaemia, loss of consciousness at the time of aneurysm rupture, day of blood sampling. } \\
\text { WWf propeptide: adjusted for amount of intracisternal blood, amount of intraventricular blood, day of blood sampling. } \\
\text { EDI fn: adjusted for amount of intracisternal blood, amount of intraventricular blood, day of blood sampling, loss of consciousness a the time of aneurysm rupture. } \\
\text { ICAM-1: adjusted for amount of intracisternal blood, loss of consciousness a the time of aneurysm rupture, day of blood sampling. } \\
\text { sP-selectin: adjusted for amount of intracisternal blood, amount of intraventricular blood, signs of acute ischaemia, loss of consciousness at the time of aneurysm } \\
\text { rupture, day of blood sampling. } \\
\text { sE-selectin: adjusted for amount of intracisternal blood, amount of intraventricular blood, signs of acute ischaemia, loss of consciousness at the time of aneurysm } \\
\text { rupture, day of blood sampling. } \\
\text { Cl, confidence interval; DCl, delayed cerebral ischaemia; HR, hazard ratio; vWf, von Willebrand factor. }\end{array}$} \\
\hline
\end{tabular}

ischaemic events from any cause showed a positive association with vWf concentrations (crude HR $=2.3(95 \% \mathrm{CI}, 1.1$ to 4.9)) (fig 2A). This association was no longer statistically significant in the multivariate analysis (adjusted $\mathrm{HR}=1.8$ $(0.8$ to 3.9$))$. The analysis of spontaneous DCI revealed a trend towards a positive association with vWf in the crude analysis (crude HR = 3.5 (0.9 to 13.1)) (fig 2B), which again weakened after adjustment in the multivariate analysis (adjusted HR $=22.2(0.5$ to 9.8$)$ ).

\section{Influence of operation}

In five of the 78 operated patients, blood sampling took place after surgical clipping of the aneurysm. All analyses were repeated after exclusion of these five patients. The associations of early concentrations of vWf with ischaemic events from all causes (crude HR $=2.4$ (95\% CI, 1.2 to 5.0); adjusted $\mathrm{HR}=2.2(95 \% \mathrm{CI}, 1.0$ to 4.9$))$, with spontaneous DCI (crude $\mathrm{HR}=3.6$ (1.0 to 13.7); adjusted $\mathrm{HR}=2.4(0.5$ to 10.6$)$ ), and with outcome (crude OR=6.4 (2.5 to 16.3); adjusted $\mathrm{OR}=3.6$ (1.2 to 10.5$))$ all became stronger. The associations of the other markers with DCI and outcome were essentially unchanged.

\section{DISCUSSION}

The main findings of our study were positive associations between early concentrations of vWf on the one hand and occurrence of DCI and poor outcome on the other, whereas there were no associations between the initial concentrations of the inflammatory adhesion molecules sICAM-1, sPselectin, and sE-selectin with either DCI or outcome.

Our investigations were based on the possibility of a positive association between circulating levels of inflammatory adhesion molecules and the occurrence of DCI that could predict DCI and would support the hypothesis of a pathogenic relation between inflammatory processes in the cerebral (micro-)circulation and the development of DCI. According to this hypothesis acute cerebral ischaemia at the time of aneurysm rupture could lead to endothelial cell activation, adhesion of activated leucocytes, and the development of inflammatory processes that would set the stage for subsequent DCI. However, this hypothesis could not be substantiated by our findings. There are only three previous reports on sE-selectin measurements in patients with $\mathrm{SAH}$, two of which described sE-selectin levels in cerebrospinal fluid. ${ }^{8}{ }^{9}$ The third study-on 36 patients with SAH-reported mean values of sE-selectin, sP-selectin, and sICAM-1, among others, in five to eight samples over two weeks, but without data on initial concentrations. ${ }^{20}$ With this method, a significant increase in mean sP-selectin levels, a non-significant increase in mean concentrations of sEselectin, and a nearly significant decrease in mean sICAM-1 concentrations in patients with DCI were found. These mean values included samples taken after the occurrence of cerebral ischaemia and after operation. This different approach makes comparison with our findings impossible. There are no other studies of sP-selectin in SAH, and there is only one other study of sICAM-1 and vasospasm in SAH. ${ }^{21}$ In that study, increased plasma concentrations of sICAM-1 were reported after the onset of vasospasm, documented by transcranial Doppler sonography or angiography. Clinical or radiological signs of DCI were not mentioned, nor were initial concentrations of sICAM-1 reported. The different goal and methodology of this study precludes comparison with our findings.

The main aim of our study was to investigate the association of initial concentrations of inflammatory adhesion molecules with DCI. Our outcome event of interest was the occurrence of delayed cerebral ischaemia, not of radiological vasospasm. The eventual goal in treating patients with SAH is to prevent the occurrence of DCI. As vasospasm does not always lead to cerebral ischaemia, DCI is a more relevant outcome measure than vasospasm from a clinical point of view. To establish the diagnosis of DCI, clinical signs and CT or MRI features are decisive, whereas transcranial Doppler or angiography do not essentially contribute. Moreover, the diagnostic sensitivity and specificity of transcranial Doppler measurements are far from optimal. ${ }^{22} 23$ Angiography is a very sensitive diagnostic tool but entails some risk for the patient. As there are no proven benefits from interventions targeted at vasospasm, we did not use angiography to diagnose vasospasm.

Our finding that there was no association between early sICAM-1 concentrations and outcome is in agreement with an earlier study. ${ }^{24}$ Although in that study mean sICAM-1 concentrations from day 2 to day 12 were associated with outcome on day 14, early concentrations of SICAM-1 on days 2 and 4 after aneurysm rupture were not associated with outcome.

The second aim of our study was to investigate whether initial concentrations of three other markers of endothelial cell activation-vWf, vWf propeptide, and EDl-fibronectincould predict the occurrence of DCI. We found a statistically significant crude positive association between raised vWf concentrations with cerebral ischaemic events from all 
causes. The crude association of vWf with spontaneous DCI was of borderline significance. The number of patients with spontaneous DCI may have been too small to show a sound statistically significant association. However, as in a previous study, we were unable to demonstrate an independent association of early vWf concentrations with delayed cerebral ischaemia. $^{18}$

We also found a positive association of raised concentrations of vWf, vWf propeptide, and EDl-fibronectin with poor clinical outcome, but only vWf was an independent risk factor for outcome. Of note, vWf was an independent predictor of outcome despite the occurrence of rebleeding later in the course of the disease, which in itself has a substantial influence on outcome.

Other studies on the issue of vWf and SAH are scant and report the relation with vasospasm but not with outcome. A recent study of plasma vWf concentrations in relation to vasospasm in 38 patients with $\mathrm{SAH}$ found a strong and significant association between vasospasm and peak vWf concentrations before the onset of vasospasm, but not of initial concentrations. ${ }^{25}$ Another study reported an independent association of vWf concentrations with cerebral vasospasm and ischaemic complications, but this association only concerned CSF concentrations and was absent with plasma concentrations. ${ }^{26}$ A small study in 21 patients with SAH, nine of whom developed delayed cerebral ischaemia, found significantly increased vWf concentrations in patients with delayed cerebral ischaemia in blood samples taken between five and nine days after the haemorrhage, but the relation with the time of onset of ischaemia was not described and no adjustment for confounding factors was made. ${ }^{27}$

Our findings show that vWf is not an independent predictor of DCI. However, our results, in conjunction with those reported by others, raise the question of a pathophysiological relation between $\mathrm{vWf}$ and DCI. A rise in $\mathrm{vWf}$ concentrations may be an epiphenomenon, merely reflecting the impact of the initial insult. ${ }^{28}$ This would explain why the crude associations with DCI disappear after adjustment for such factors as loss of consciousness or signs of acute ischaemia at the onset of SAH, WFNS score, or the amount of blood on the initial CT, all measures of the severity of SAH. However, this explanation does not exclude the possibility that increased vWf concentrations may play a role in the pathophysiology of complications of SAH.

The functions of vWf are to promote the adhesion, and subsequent aggregation, of platelets to thrombogenic surfaces, such as the subendothelial matrix after denudation of the endothelium, and to serve as a carrier for coagulation factor VIII. ${ }^{29}$ In SAH, the platelet adhesion function will take place primarily at the site of aneurysm rupture, where vWf binds to receptors of the subendothelial layers and platelets bind to immobilised vWf. If, however, acute cerebral ischaemia injures endothelial cells to such an extent that vWf can attach to subendothelial receptors, multifocal thrombosis in the cerebral (micro-) circulation may be enhanced by increased concentrations of vWf.

In the last decade it has become apparent that vWf also promotes platelet to platelet adhesion if platelets are activated and the shear rate is high. ${ }^{29}$ Previous studies showed that platelets may indeed be activated after SAH. ${ }^{30}$ Therefore, increased local vWf concentrations in SAH may induce the formation of microthrombi in the cerebral arteriolar circulation where shear rates are high. vWf normally enters the circulation through constitutive secretion. In the case of stimulation of endothelial cells a second pathway of regulated secretion of vWf may lead to presence of so called unusually large vWf multimers, which have an increased thrombogenic potential. ${ }^{29}$ These molecules may further enhance the formation of microthrombi and the occlusion of small vessels. If a causal role for vWf in the development of DCI after SAH can be confirmed in future research, this will support preventive trials of inhibitors of platelet aggregation, or even antibodies against (activated) vWf, in patients at risk of DCI.

\section{Conclusions}

Our study convincingly shows that concentrations of the inflammatory adhesion molecules sICAM-1, sP-selectin, and sE-selectin measured early after onset of SAH do not predict the occurrence of DCI or outcome. The positive associations of vWf concentrations at entry with DCI and outcome suggest that increased concentrations of vWf can lead to formation of microthrombi in the cerebral circulation. These may cause impaired recovery from acute cerebral ischaemia or predispose to secondary ischaemic injury, with a negative influence on clinical outcome.

\section{ACKNOWLEDGEMENTS}

GJER was an established clinical investigator of the Netherlands Heart Foundation during the conduct of the study (D98.014). The laboratory investigations were made possible by a grant from the Netherlands Heart Foundation (98.059) and the "Landsteiner Stichting voor Bloedtransfusie Research" (9922). Both foundations have not been involved in any aspect of the performance of the study. We kindly acknowledge the assistance of D Castigliego and E Sellink with the laboratory assessments, and the statistical advice of I van der Tweel.

\section{Authors' affiliations}

C J M Frijns, J van Gijn, G J E Rinkel, Department of Neurology,

University Medical Centre Utrecht, Utrecht, Netherlands

R Fijnheer, Department of Haematology, Research Laboratory,

University Medical Centre Utrecht

A Algra, Julius Centre for Health Sciences and Primary Care, University Medical Centre Utrecht

J A van Mourik, Department of Plasma Proteins, Sanquin Research at CLB and Department of Vascular Medicine, Academic Medical Centre, University of Amsterdam, Amsterdam, Netherlands

Competing interests: none declared

\section{REFERENCES}

1 Hop JW, Rinkel GJ, Algra A, et al. Case-fatality rates and functional outcome after subarachnoid hemorrhage: a systematic review. Stroke 1997;28:660-4.

2 Dumont AS, Dumont RJ, Chow MM, et al. Cerebral vasospasm after subarachnoid hemorrhage: putative role of inflammation. Neurosurgery 2003;53:123-35.

3 Handa $Y$, Kubota T, Kaneko M, et al. Expression of intercellular adhesion molecule 1 (ICAM-1) on the cerebral artery following subarachnoid haemorrhage in rats. Acta Neurochir Wien 1995;132:92-7.

4 Bavbek M, Polin R, Kwan AL, et al. Monoclonal antibodies against ICAM-1 and CD18 attenuate cerebral vasospasm after experimental subarachnoid hemorrhage in rabbits. Stroke 1998;29:1930-5.

5 Sills AK, Clatterbuck RE, Thompson RC, et al. Endothelial cell expression of intercellular adhesion molecule 1 in experimental posthemorrhagic vasospasm. Neurosurgery 1997;41:453-60.

6 Oshiro EM, Hoffman PA, Dietsch GN, et al. Inhibition of experimental vasospasm with anti-intercellular adhesion molecule-1 monoclonal antibody in rats. Stroke 1997;28:2031-7.

7 Aihara $\mathrm{Y}$, Kasuya $\mathrm{H}$, Onda $\mathrm{H}$, et al. Quantitative analysis of gene expressions related to inflammation in canine spastic artery after subarachnoid hemorrhage. Stroke 2001;32:212-17

8 Gaetani P, Tartara F, Pignatti P, et al. Cisternal CSF levels of cytokines after subarachnoid hemorrhage. Neurol Res 1998;20:337-42.

9 Polin RS, Bavbek M, Shaffrey ME, et al. Detection of soluble E-selectin, ICAM1 , VCAM-1, and L-selectin in the cerebrospinal fluid of patients after subarachnoid hemorrhage. J Neurosurg 1998;89:559-67.

10 Barone FC, Feuerstein GZ. Inflammatory mediators and stroke: new opportunities for novel therapeutics. J Cereb Blood Flow Metab 1999; 19:819-34

11 Enlimomab Acute Stroke Trial Investigators. Use of anti-ICAM-1 therapy in ischemic stroke: results of the Enlimomab Acute Stroke Trial. Neurology 2001;57:1428-34.

12 Peters JH, Sporn LA, Ginsberg MH, et al. Human endothelial cells synthesize, process, and secrete fibronectin molecules bearing an alternatively spliced type III homology (ED1). Blood 1990;75:1801-8. 
13 Fijnheer R, Frijns CJ, Korteweg J, et al. The origin of P-selectin as a circulating plasma protein. Thromb Haemost 1997;77:1081-5.

14 Glukhova MA, Frid MG, Shekhonin BV, et al. Expression of extra domain A fibronectin sequence in vascular smooth muscle cells is phenotype dependent. J Cell Biol 1989; 109:357-66.

15 van Mourik JA, Boertjes R, Huisveld IA, et al. von Willebrand factor propeptide in vascular disorders: $A$ tool to distinguish between acute and chronic endothelial cell perturbation. Blood 1999:94:179-85.

16 Drake CG. Report of World Federation of Neurological Surgeons Committee on a Universal Subarachnoid Hemorrhage Grading Scale. J Neurosurg 1988;68:985-6.

17 Hijdra A, Brouwers PJ, Vermeulen M, et al. Grading the amount of blood on computed tomograms after subarachnoid hemorrhage. Stroke 1990;21:156-61.

18 Frijns CJ, Rinkel GJ, Castigliego D, et al. Endothelial cell activation after subarachnoid hemorrhage. Neurosurgery 2002;50:1223-9.

19 Bamford JM, Sandercock PA, Warlow CP, et al. Interobserver agreement for the assessment of handicap in stroke patients. Stroke 1989;20:828.

20 Nissen JJ, Mantle D, Gregson B, et al. Serum concentration of adhesion molecules in patients with delayed ischaemic neurological deficit after aneurysmal subarachnoid haemorrhage: the immunoglobulin and selectin superfamilies. J Neurol Neurosurg Psychiatry 2001;71:329-33.

21 Mocco J, Mack WJ, Kim GH, et al. Rise in serum soluble intercellular adhesion molecule-1 levels with vasospasm following aneurysmal subarachnoid hemorrhage. J Neurosurg 2002;97:537-41.
22 Treggiari-Venzi MM, Suter PM, Romand J-M. Review of medical prevention of vasospasm after aneurysmal subarachnoid hemorrhage: a problem of neurointensive care. Neurosurg 2001;48:249-61.

23 Creissard $P$, Proust $F$, Langlois $O$. Vasospasm diagnosis: theoretical and real transcranial Doppler sensitivity. Acta Neurochir Wien 1995;136:181-5.

24 Mack WJ, Mocco J, Hoh DJ, et al. Outcome prediction with serum intercellular adhesion molecule-1 levels after aneurysmal subarachnoid hemorrhage. J Neurosurg 2002;96:71-5.

25 McGirt MJ, Lynch JR, Blessing $R$, et al. Serum von Willebrand factor, matrix metalloproteinase-9, and vascular endothelial growth factor levels predict the onset of cerebral vasospasm after aneurysmal subarachnoid hemorrhage. Neurosurgery 2002;51:1128-34

26 Beuth W, Kasprzak H, Wozniak B, et al. Von Willebrand factor in patients with subarachnoid hemorrhage. Neurol Neurochir Pol 2001;35(suppl 5):130-4.

27 Hirashima Y, Nakamura S, Endo S, et al. Elevation of platelet activating factor, inflammatory cytokines, and coagulation factors in the internal jugula vein of patients with subarachnoid hemorrhage. Neurochem Res 1997:22:1249-55

28 Mannucci PM. von Willebrand factor: a marker of endothelial damage? Arterioscler Thromb Vasc Biol 1998; 18:1359-62.

29 Ruggeri ZM. Structure and function of von Willebrand factor. Thromb Haemost 1999:82:576-84.

30 Juvela $\mathrm{S}$, Hillbom $M$, Kaste $M$. Platelet thromboxane release and delayed cerebral ischemia in patients with subarachnoid hemorrhage. J Neurosurg $1991 ; 74: 386-92$ 